\title{
Repercussions of Singularity of Site Authorities in Making Heritage Conservation Decisions: Evidence from Iraq
}

\author{
Mohammed Awadh Jasim*, Laura Hanks and Katharina Borsi \\ Department of Architecture and Built Environment, University of Nottingham, Nottingham, United Kingdom \\ * Corresponding author: mohammed.jasim@nottingham.ac.uk
}

\begin{abstract}
Different global assertions have recently been made prohibiting the mono approach of decisionmakers in formulating heritage conservation policies, due to many unfavourable touristic and political implications. The mono approach has led to exploitation of some sites' cultural standing as well as condoning a veritable remedy of some of their social and urban aspects, and thus threatening these sites with exclusion from the World Heritage List. This paper investigates the approach of some local Iraqi experiences of conservation, aiming at revealing some of the more painful repercussions of the singularity of site authorities in planning for built heritage future, which may draw a plan for the site away from its heritage potential. Some local cases are reviewed here, such as Erbil Citadel, setting them as examples that may add more facts to the global experience of heritage conservation in this regard. The paper concludes that the site authorities are also liable to drift as a result of some ramifications that impede setting a deep-sighted strategy, and thus may stray far from delivering the far-reaching aims. Accordingly, the monaural authority approach may need to be synthesised with some of the site's locally-based views through an overlapped integral loop of interactions between them, which may support the conservation policy-formulation with diverse contributions.
\end{abstract}

KEYWORDS heritage conservation policies, heritage decision-makers, top-down approach, local views, Babylon, Erbil Citadel

Received August 31, 2017; accepted January 18, 2018.

\section{Introduction}

More than global affirmation precludes the strict topdown control of planning for the future of built heritage sites, including their conservation policies; as a result of many impacts, some of them have been threatened with exclusion from the World Heritage List (WHL) (Hewiston 1987). Despite some heritage's authorities excessively adopt some global heritage charters as if they were 'articles of faith' (Avrami, Mason and De La Torre 2000), there is still a great lack of real activation of some articles within these charters, which inhibits the power of the decisionmakers from strictly controlling the conservation policies of these sites. It is thus requisite to reconsider the constant emphasis of these charters on preventing the politicising of heritage conservation policies and instead they should prioritise the site's problems and potentials (ICOMOS 1999; ICOMOS 2013a). What makes some local authorities flounder in such a way is perhaps not necessarily a weakness in the charters but rather a superficial reading of them as well as selecting from only one side of the charter to deliberately focus on what will seemingly facilitate the encoded purposes of the top-down policy. Consequently, the other side of these charters is left deactivated, which might highlight the need to share the conservation policymaking among different parties who together could develop more realistic plans and efficient decisions for the future of these treasured sites (Carlsson and Berkes 2005).

Erbil Citadel is described as 'an ancient city built on top of an artificial mound raised up by the successive rebuilding of houses and other structures on top of each other over thousands of years (Brammah 2009a, 67). Its conservation experience(s) have lacked the activation of both sides of the global charters, which has led to various negative impacts on the site. Whilst these negative impacts might be attributed to more than this one factor, the Iraqi conservation laws, including decision-making structures, 
can be set main amongst them. Subjectivity in the heritage conservation decision-making process can be seen as a two-way track. The first track is argued to be pertinent to the views on the grassroots level of these sites (Taylor 2004; Silva and Chapagain 2013). In addition, through Erbil conservation experiences, the study attempts to show that also its second track is prone to being dominated by the individual top-down attitudes of the conservation decision-makers. The paper aims at revealing the negative implications-based singularity of the current decisionmaking process of Erbil Citadel's revitalisation project and to show how pluralism should be involved instead to avert subjectivity and its destructive impacts on the site. To attain this, it reviews some local experiences in this respect, showing how the pre-set top-down purposes are set as indisputable goals, whereas any other potential of these sites should be complementary and/or supportive to these goals.

A qualitative analytical approach is employed here through which, firstly, some key literature can be reviewed to demonstrate the significance of integrating these purposes with the views of locals and specialists when planning for built heritage sites. Secondly, it investigates how the findings of this review have been employed by the authorities when making those sites' policies. This, on the one hand, may inform the study about the role of the site authorities in maintaining efficient association with the other parties surrounding conservation policy-making, and how the local conservation laws sustain this, on the other. The paper concludes that the primacy in heritage conservation decision-making should not be a monopoly of the site authorities only, but heritage experts and specialists as well as local communities should also be taken into consideration in this regard. To say that the site authorities should possess the leadership baton of the conservation policy-formulation seems unpliable in many sites today, and thus it needs to be intermingled with those global experts and involve some bottom-up views from the site. This might lead to more neutrality when drawing the future aims of built heritage.

Two conservation processes in Erbil Citadel will be narrated here (debated through some other local experiences), showing how the top-down approach acts when it has a complete control on the decision-making process of built heritage. What makes Erbil's current revitalisation different from its former renovation is that the repercussions of its top-down decisions are still having implications upon the site currently, as they completely negate its ancient past and thus contradict its futuristic aim.
Furthermore, and based on this, the recent Report on the site by ICOMOS (2014), also urges deepening the grounds behind these repercussions, making the focus on this revitalisation a key issue here.

\section{Imperatives behind a Co-decision of Heritage Conservation Process: Building a Theoretical Framework}

Today, the cultural importance of our built heritage is increasingly viewed as a cultural value for the entire place to become an essential part of its cultural identity. Therefore, a rich body of literature, such as Chitty (2017), Jokilehto (2017), Jasim et al. (2017), and Kriken and Enquistand (2010), indicate, explicitly or implicitly, that heritage decision-making cannot be tied to the site's authorities for there may be a plethora of impacts of such a move. For instance, authorities' control on conservation policies may jeopardise heritage privacy for a number of reasons. Firstly, there may be high reliance on the international ICOMOS charters, and tracing their norms and rules may globalise the site's local settings instead of protecting them. Secondly, the overall plan to conserve the site, sometimes, fails to show real attempts of scrutinising the site's authenticity and its deep-seated cultural values. Yet, this also may be attributed to an incomplete investigation of the deep-rooted sociocultural assets of the site, which may demand material involvement of heritage's local communities. Moreover, authorities' control on heritage decision-making might breed a visual and cultural gap between the traditionalism of heritage and the modernity of the surroundings. Additionally, it may indicate some fragility in its self-evaluation, imprecision of objectives and impracticality of problem-solving. In fact, all of that represents the case of many Asian heritage sites, which Iraq, in general, and Erbil Citadel, in particular, is part of.

According to Jokilehto (2017), the historic town of Icheri Sheher, Baku-Azerbaijan (inscribed on the WHL in 2000) may show what supports these claims. The site has experienced a top-down conflicting policy that controversially detaches its centre from its periphery, seeking to open the site towards some contemporary architectural aspirations that leave its history aside, invoking instead Dubai as an inspiration. As a result, the site's central area suffered a state of solitude, as its surroundings have left their traditional features behind in favour of high-rise buildings and a clear globalised style. Within this context, Chitty $(2017,23)$, affirms that 'each [site] has its specificity', which makes it subject to 


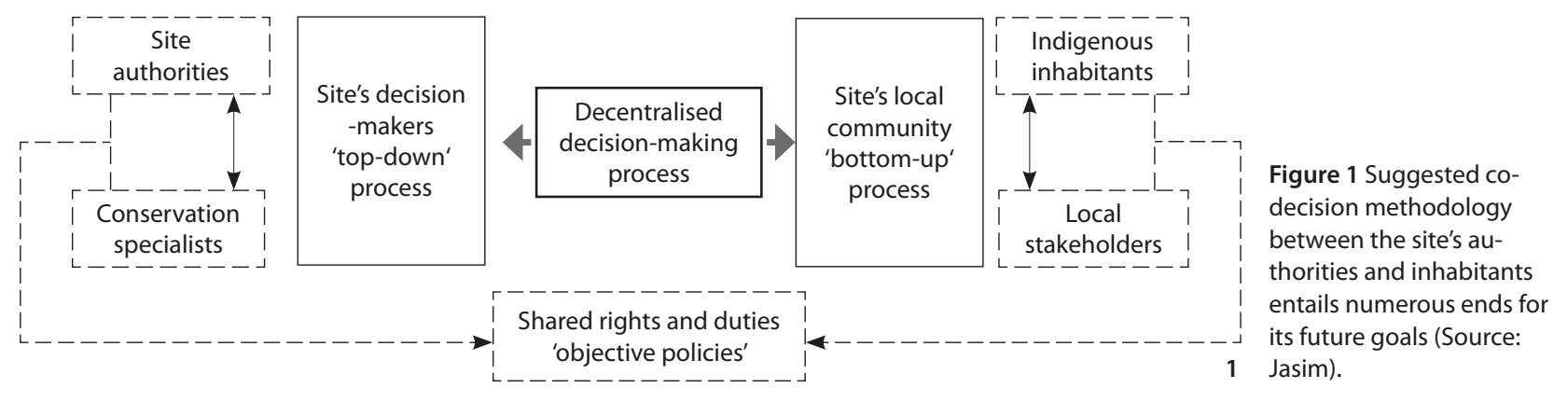

refutation whether these top-down methodologies are really capable of maintaining such specificity, and thus local settings of the site. This, in fact, is an issue that such globalised methodologies could not often challenge, and many objections have been raised against them within many Asian sites. The Suleymaniye and Zeyrek quarters in Turkey (inscribed on the WHL in 1985), for instance, can be set as an example of this when the traditional urban fabric of the site has been demolished for some top-down aspirations that failed to match the same level of authenticity, and consequently the site has been semideserted by its inhabitants.

On the contrary, in Harar Jugol, Ethiopia, overlapping the top-down role with a bottom-up one has meant there has been some success in maintaining the traditional fortified town (inscribed on the WHL in 2006). The contributions made there vitally contributed to the continuity of its sociocultural traditionalism, whilst also maintaining a viable relationship with the modern surroundings (Jokilehto 2017). Also, an alternative future plan has been drawn up for Borobudur heritage site by its locals, replacing a monaural top-down policy that would have led to globalising the traditional features of the site, which instead provided a more substantiated vision of the site's traditional assets (Hampton 2005).

Accordingly, Jokilehto (2017) and Chitty (2017), note that purely top-down policies even with high levels of professionalism, sometimes, cannot seize the diversity of sociocultural assets that many of the built heritage sites possess. The developmental policy of Asmara site in Eritrea gives an example of this. The diversity of the site's sociocultural history, which has experienced three different epochs of culture belonging sequentially to Italian, then English colonisers, and then Ethiopians until the 1990s has conditioned the dynamic involvement of its inhabitants. Jokilehto (2017) considers their collective and accumulative awareness regarding the site culture, which appears to be a crossroads of three cultural stages, as essential for setting realistic policies and feasible goals. As such, to prevent the top-down control on heritage decisions, Carlsson and Berkes $(2005,65)$ suggest a codecision policy between these two powers, which offers 'a continuous problem-solving process, rather than a fixed state, involving ... negotiation within problem-solving networks' (Figure 1).

Such a co-policy leads to a 'dynamic participation of purposeful concepts'; 'conflicts control'; 'establishing a level of equality'; and consequently, 'a more comprehensive process of decision-making' regarding the site's future aims. This in fact is often attributed to 'narrating stories with unflagging gusto of the local communities that always increase the tourist-cultural significance of built heritage' (Jasim, Hanks and Borsi 2017, 291-297). Thus, critical discourse of heritage scholars should receive real attention from heritage authorities and other top-down conservation policy-makers.

\section{Positioning Erbil Citadel into this Context}

Inspiring some Western norms of urban planning superficially has dragged the urban policies of some Iraqi cities including Erbil to embed new rules into their structures, which are non-corresponding with their local traditional environments. This has led to affecting the traditional Iraqi city significantly in terms of subjecting some of its local norms to new global criteria. Within this context, Rebwar, Mushatat and Abdelmonem $(2014,58)$, who investigated the repercussions of top-down urban politics upon 'Reshaping the Urban Form of Erbil City' in the recent decades, indicate that lack of clear urban policies that can flexibly unify the traditional with the contemporary has led the urban context of the city to be 'stretched between ... two ends of ... authentic quarters with its traditional fabric and modern districts with their global sense of living.' Currently, Erbil suffers a state of 'randomness and disarray in the physical form, in which both old 
and new, the traditional and the modern appear alien to each other' (Rebwar, Mushatat and Abdelmonem 2014, 59). Its fast regeneration has resulted in 'the emergence of neoliberal urbanism' within its developmental policies, where the conservation laws of its Citadel did not deviate from its implications enough (Yasin 2011).

For instance, the reliance on some Orientalist studies, which believe in a state of chaos within some 'principles of Islamic urbanism based on issues of cohesion, equality and proximity' (Rebwar, Mushatat and Abdelmonem 2014,61 ), has led to a distortion of the traditional form of Erbil Citadel with new modern additions, such as the new central street that has split the site into two halves (Nooraddin 2012). Secondly, their 'economic sanctions' disconnect the surroundings from the Citadel, which pursues western visions that materialise some urban economic schemes and celebrates their capitalist agenda (Rebwar, Mushatat and Abdelmonem 2015; Yasin 2011; Ismail and Ngah 2010). Moreover, the recent hasty spatial expansion accompanying Erbil's 'urban growth ... compounded by a dramatic increase in population' has deformed the Citadel's authentic social structure by new arrivals that dwelled the site (Rebwar, Mushatat and Abdelmonem 2015, 14). This, indeed, led to a state of plotting against the Citadel's 'unique architectural characteristics and the spatial urban aspects ... that preclude motorised transport and enclosed by town walls' (Rebwar, Mushatat and Abdelmonem 2014, $61)$. Hence, the Citadel really challenges urban, architectural, visual and cultural changes that are decisively striking its ancient heritage (Aljanabi 1987; HCECR 2012c; Rebwar, Mushatat and Abdelmonem 2015). All of this might be nothing but repercussions of the non-insightful visions that some top-down urban policies have brought to the site. Rydin (2010) and Ebraheem (2013), write that this simply shows the kind of incidental mass-production of unsustainable approaches and unplanned projects that have accumulated at the centre of the city, which impacted the Citadel's heritage ultimately.

\section{Erbil Citadel Renovation Process}

As a consequence of time factors along with the increasing need to link the site with some modern services, a controversial renovation process took place in the late 1970s, which resulted in different types of deterioration of the urban structure of the Citadel. In fact, some references, such as (Novacek et al. 2008; HCECR 2012a; SOITM 2013), point out that the process perfectly reflected the paradigm of singular decision-making by the site authorities, ignoring any potential role that could have been played by any other parties, such as the local community of the site. The latter is often considered by different global heritage organisations, such as UNESCO and ICOMOS, as 'the relevant knowledge holders' for such sites. Consequently, 'their traditional knowledge and experience must be appropriately used and valued' in any endeavour to conserve these sites (ICOMOS 2013b, 3 ). This is largely because it is 'the best ... to comprehend the spirit' of these sites, and thus 'should be intimately associated in all endeavours to preserve and transmit' their cultural significance to the next generations (ICOMOS 2008, 4). Based on this, the present-day conservation theory seeks to involve diverse, and even fragmented, contributions from the inhabitants 'to engage in a profound and coherent analysis of the ideas' (Vinas 2005 cited in Hidaka, 2008, 6). Taylor (2004), and Silva and Chapagain (2013), emphasise that such contributions facilitate an objective analysis regarding diverse heritage issues resulting from their mutual relevance with some values, traditions and meanings emanating from that particular site.

Yet, the Final Report on the site for Brammah (2009a), perhaps shows a weak co-mechanism of making the renovation decisions between the site's authorities and inhabitants, which has led to creating a clear cultural gap between the traditional local settings of the site and the contemporary policies that the renovation evokes. The Report indicates that the renovation decision to demolish the central area of the site and replace it with 'the construction of the [modern] road' for vehicles that split the site into two parts (Brammah 2009a, 68) seems contrary to the traditional Islamic urban norms that the site relies on. The site deeply celebrates the principles of overlap and compatibility within its urban scene. Yet, the decision regarding 'the demolition of the grand gate' also negates the site's architectural values when replacing it with a design that holds completely different architectural settings contradicting the site's historical assets (Brammah 2009a, 68) (Figure 2a, Figure 2b). Both of these decisions seemed as if they were 'deliberate demolitions' of this residential settlement as they lack a factual contribution that stems from the site's reality, which could really contribute to solving its problems.

Based on their deep and mutual experience with the site, the locals' involvement would probably have been able to present such solutions. Yet, the one-way decisionmaking process of the renovation has prevented this opportunity, leading to 'inappropriate' outcomes resulting from its complete detachment from the site topology 

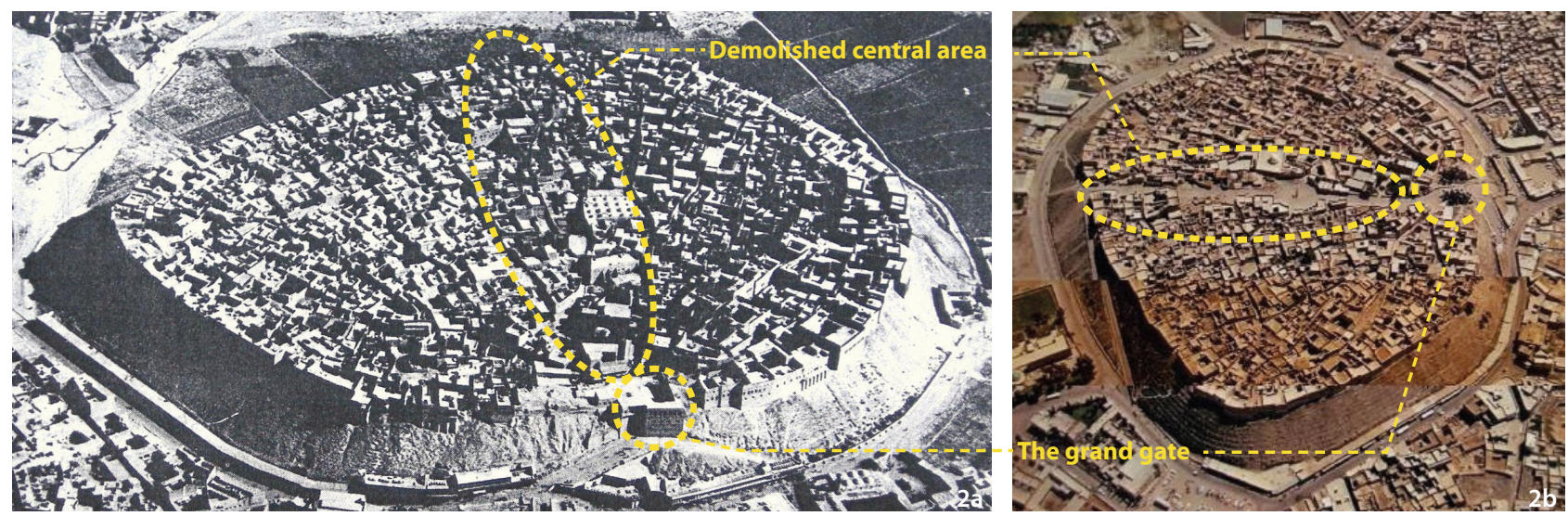

Figure 2a The Citadel in 1951, before the renovation (Source: Brammah). Figure $\mathbf{2 b}$ The Citadel after 1979, after the renovation (Source: Brammah).

(HCECR 2012a, 1). This, indeed, discloses the indifference of the renovation policy-makers towards the locals' views, who in return have shown their 'overwhelming feeling' regarding the impacts upon the site (HCECR 2012a, 1).

A series of interviews conducted with the HCECR's Office Manager and a group of professionals from the site's indigenous inhabitants in late 2014 'whether the renovation has maintained any level of co-mechanism with other local parties, such as the site's locals, in making its decisions' indicates a mutual view among the participants showing that the renovation did not reflect any level of co-mechanism between them and its policy-makers in making the site's decisions. 'Simply, the renovation decisions were made in Baghdad to be executed on the site without any veritable considerations for any actual relationship with the privacy and local settings of the Citadel or any participatory role with the inhabitants, says a managerial-political figure, who is an indigenous inhabitant of the site. The owner of the Traditional Qalat Museum of the site says, 'As an indigenous resident of the site, I can confirm to you that I have not received any invitation, calling me to participate in the future plan of my home the Citadel.' It seems that the renovation project did not consider the fact that the site was teeming with residents who may have had data that could be supportive for its policies and help it to meet its aims objectively. A religious figure, who is an indigenous citizen of this settlement, affirms that: 'I have not met with any committee who belonged to the renovation at that time ... What happened ... was ... a sample of what most of the traditional works that were planned and implemented at that period: purely top-down orders.'

The HCECR's Office Manager assigns this weakness to 'the power granted to the renovation policy-makers, which gave them an authority to draw up these decisions apart from the site that led to some agonising impacts on it?. In this regard, the HCECR (2012b) reports that the repercussions of those impacts have exacerbated upon the site, which left continuous deterioration of its urban structure and histo-cultural values that necessitated a comprehensive process of revitalisation for this habitation after 2006.

What might be inferred here is that the mono role of the site's centralised authority often grants privileges to some self-maintained top-down policies and condones any other contributions that are not subject to this role. The main cause behind that is perhaps rooted in the regional criteria of these sites through which their conservation processes are run. Some studies underline this consequence accentuating that the deactivation of the affirmative role of the co-decision-making process can be attributed to the lack of awareness of the potential bottomup contributions in some Asian heritage sites. Such contributions are 'an issue that received little attention' (Uriely, Israeli and Reichel 2003, 69), due to either the dominating role of the site's centralised authority, or a cryptic neglect resulting from the conservation criteria governing the site's future policies. Supposedly, such a weakness in the experience of renovation should be set as a lesson to the current revitalisation of Erbil in order to be avoided in its current policies at the site.

\section{Erbil Citadel Revitalisation}

In addition to the inclusion of the Citadel into the WHL, the primary aim behind the revitalisation project is to crown the site with eminent status within the scope of global heritage tourism, exploiting its unique feature of being the oldest continuously inhabited citadel in the world, and for which the Citadel is globally well-known 
(Brammah 2009a; MacGinnis, 2013). To this end, the revitalisation policy should therefore be undertaken in conjunction with the $\ldots$ inhabitants, ... encouraging the revival of [its local] identity' (Brammah 2009b, 23, 26). This conjunction enables the involvement of diverse local views, and thus more ideas regarding how to sustain this unique residential feature of the site, which assists in 'promoting knowledge of the Citadel ... significance to a local and global audience' (Brammah 2009b, 26). This entails two points. Firstly, the predominant residential character of the site should be really well considered by the revitalisation policy while planning for this aim. Secondly, it is crucial that the repercussions of the singularity of site authorities in making the previous renovation decisions should also have been set as a lesson for this revitalisation project in order not to expose the site to more deterioration. Unfortunately, there is proof that perhaps reveals less encouraging outcomes, which may prove the indifference shown when it comes to sustainability of the site's residential character in favour of other cultural-tourist purposes.

\section{First: Site-Based Evidence}

A second series of interviews with the site's authorities and inhabitants conducted in 2015 regarding 'whether the site maintains its residential character after being revitalised?' may show the non-idealistic exploitation of this unique residential trait within the site's touristic aims. Firstly, a group of specialists from the local authorities who have influence over the revitalisation policies, such as the Ministry of Culture, the General Tourism Sector in Erbil and the HCECR Commission, concurrently agree that the current residential trait for which the site is well-known globally will undergo a significant shift towards global tourism. Those conspicuous residential units in the site will be shifted from their current traditional residential activities towards new cultural functions in order to feed into the new global tourist target envisaged for the Citadel. The Ministry of Culture and the former Head of the Citadel Conservation Commission, for instance, state that the Citadel's current residential settings will be reemployed to occupy new cultural functions just to boost the site's global tourism:

Commonly, the Citadel is a residential zone; that was in the past. Henceforth, the site should represent another turn for Erbil City: it is the turn of the cultural tourism...; only a sample from the residential units will be maintained ..., informing the visitor about its traditional residential trait.
The next move to the site not only confirms this tourist shift as a new trajectory for the site, but declares that the site is considered an icon for Erbil, and the whole of Kurdistan, consequently holding some political dimensions. Thus, its residential trait should not come first, henceforth. Here, the formal spokesman for the tourism sector as represented by the General Tourism Commission in Erbil confirms:

The site has come to represent a brand for Kurdistan presently, and started to be seen as a robust marketable tool for the global tourism to become a global tourist site. In return, the HCECR should work on the definition of the site within an appropriate level of international tourist representation.

The HCECR Commission, which did not object to the fact that the site definition will be converted from habitation to tourism, points out that the possible role entrusted to the site's inhabitants to achieve this definition would be minimal, owing to the fact that the debate around the future of the site is less connected to its inhabitants. According to the Head of the HCECR, 'discussing the future aspirations of the revitalisation policy rests with the Commission more than the site inhabitants'.

In fact, the new shift of the site is confirmed in more than evidence. Firstly, the UNESCO Report (2014), shows that its residential sample is to serve as a gesture to the Citadel's 'daily social life' to be 'integrated with the presence of cultural activities... and sustainable tourism development' of the site (UNESCO 2014, 127), regardless of the global insistence on demonstrating the spirit of the original use for which the [site] was designed, which is residential (UNESCO 2014, 125). Secondly, the Outputs of the Revitalisation (2009), suggests establishing a 'Heritage House' unit, which 'will serve as the base... for attracting investment for ... tourism development' (Brammah 2009a, 75) that would further this aim. The 'Priority Quadrant' proposal also shows how some suggested tourist purposes dominate the future plan of the site (Figure 3). Perhaps, this gestures to two points. Firstly, the current revitalisation policy does not pay attention to the site's feature of being the oldest site continuously inhabited so far, consequently depriving site of its unique feature that could attract tourists. Secondly, it ignores the locals' role in supporting this aim. Whilst, as part of the author's position with the HCECR as a Senior Architect between 2007/8, some surveys conducted in the lower area surrounding the site have shown their positive contributions on this aim, such as revealing some social 


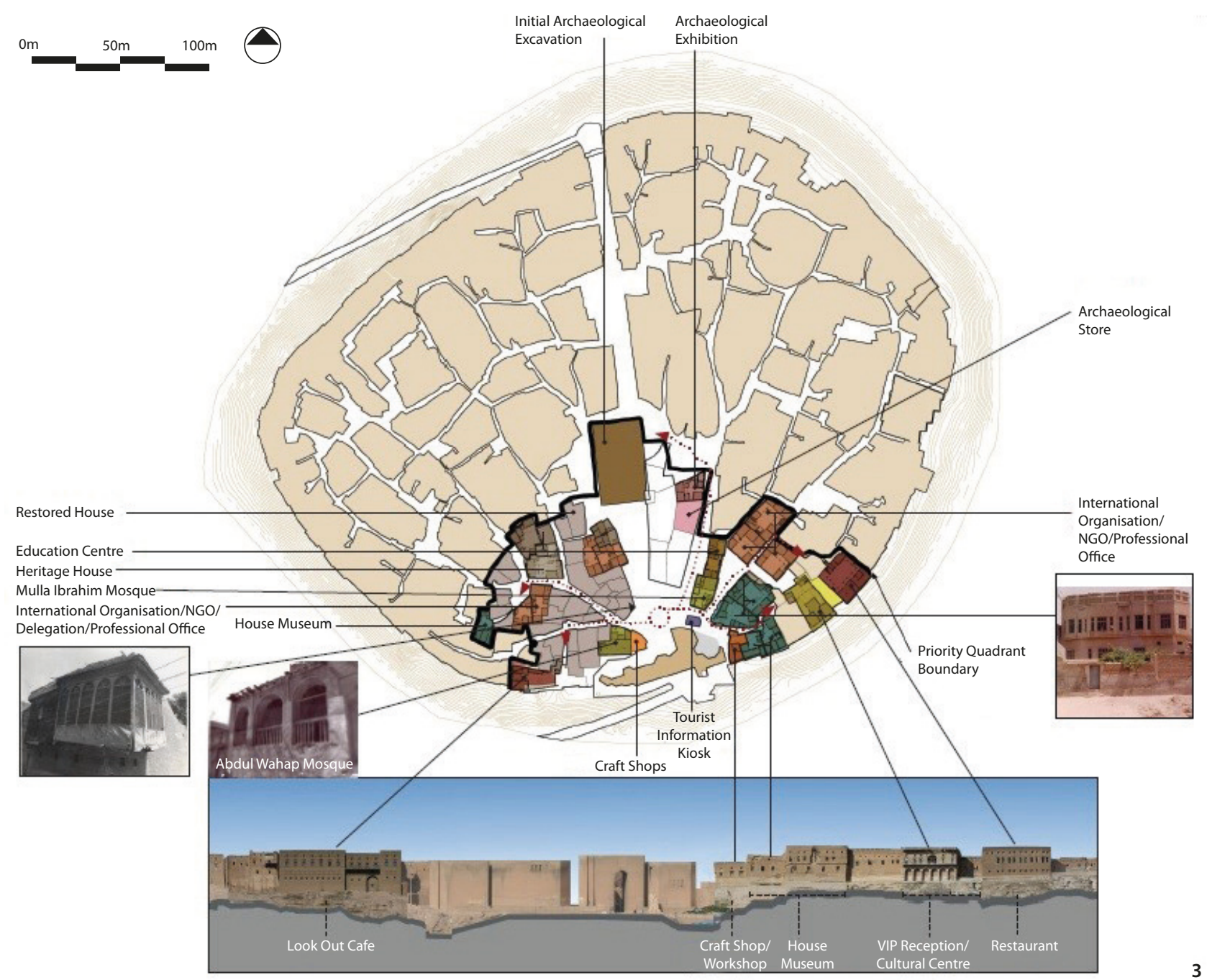

Figure 3 Priority quadrant land use proposal; which combines different cultural and recreational functions supporting the tourist goal of the site in the; maintained architectural elements, but cancelled residential functions (Source: Huszar Brammah).

norms inherent in the site; detecting many of its obsolete architectural details; picturing some key historical stories submerged in the site's cultural layers; and thus, their performance as a 'storytelling' for the recreational journey of the built heritage.

However, another group of interviews among the site's indigenous inhabitants conducted in 2015 affirms that the first stages of the revitalisation process were firstly empty from any actual steps regarding sustaining the continuity of the residential character of the site. Secondly, therefore, their participatory role has been given less attention for achieving the site's new tourist features. An indigenous managerialpolitical figure, concurrently with a religious figure from the site revealed that 'the first decision that was made for the site was the decision to clear the site of its inhabitants ... All the major decisions of the revitalisation process were made subsequently ... This led the site to becoming owned by the government in order to be prepared for this tourist turn'.
In fact, this may prove that the site's tourist potential is initially set as a far-reaching goal for its future, whereas the idea of sustaining its residential character probably was forgotten from being one of the pillars of this potential. Instead of annulling its role, setting the site as a 'brand for Kurdistan' in the global tourism arena, it might need to maintain its uniqueness of being 'the oldest site continuously inhabited so far'. Consequently, the site's residential character should be well-considered as a potential for succeeding in this aim. Touristically, this can have many constructive impacts on this aim particularly as it maintains the site vibrancy through sustaining its social composite, and thus presenting the site to the visitor teeming with social life rather than as a deserted place. As a consequence, it exposes its tourist aim to the inhabitants' live views, which may support this aim with feasible ideas whereby different economic implications would be targeted in the cultural storytelling of these views (Nicholas 2009). 
Thus, though the endeavour to mark the site out as a national Kurdish symbol and use it as a tool for tourism marketing is cherished, still the evacuation step to clear the site of its people is premature, and ultimately breaks the residential continuity of the site for which the Citadel is globally recognised. Secondly and consequently, instead of combining more efforts to stop the site's physical continuous deterioration, in fact, the evacuation has exacerbated that. To be a global tourist venue, the site's ongoing collapses should be controlled as a priority. The evacuation has deprived the site of many realistic views of the inhabitants who have witnessed most of these collapses, and thus, their views could serve in this regard. Some global experts of the revitalisation project indicate that the evacuation step cancels out real efforts of true contributions that might disclose different solutions to control these collapses, which ultimately serve the tourist aim of the site.

\section{Second: UNESCO \& ICOMOS-Based Evidence}

The ICOMOS Report on the site (2014), directly refers to the evacuation step as a real inconsistency in the revitalisation policy, which impedes the formal inscription of this settlement into the WHL. The contradiction here is through celebrating the site on paper (being the oldest site continuously inhabited so far) and ignoring this fact on the ground (through the evacuation). The Report discloses this paradox in more than one place in the Dossier of nomination of the site to the WHL. For instance, the ICOMOS shows that the Dossier repeatedly stresses the importance of the residential character of the site, stating: 'Erbil Citadel stands alone for its continuity of settlement ...; the millennial continuity of occupation of the Erbil site is also attested to be the remarkable permanence of its name...' (ICOMOS 2014, 3-5) ICOMOS continues: 'The fact that Erbil Citadel is currently uninhabited detracts from its sense of place as a town ... and in this regard the ... revitalisation formulas appear excessively tourism-oriented and do not pay attention to the regeneration of the social fabric within the Citadel.' (80-86)

If this step is to prepare the site for its global tourist shift, it has led the property to lose its social vibrancy as it has been emptied of its residents, which ultimately impacts this shift in a negative manner. This discrepancy has left the Dossier unable to present evidence consolidating its main themes. For instance, the Dossier indicates the Citadel's 'continuity of occupation and still surviving urban character', but it does not present proof stressing 'the surviving physical evidence of the Citadel' (ICOMOS 2014, $3-5)$, as well as a lack of information on the chronological modification that most of the houses have witnessed. Also, the Dossier does not 'provide historical and archaeological evidence for this change. Neither a construction date, nor [evidence] on the building materials ... in relation to the former walls' of the site's constructs (ICOMOS 2014, 8387). All of this may more easily have been achieved if the inhabitants had been actively participating and seen as 'the first' to be responsible for these modifications, and that their evacuation 'ha[d] not been justified' (ICOMOS 2014, 3-5). Therefore, 'ICOMOS recommends that the HCECR ... foresees the return of former inhabitants' (ICOMOS 2014,87 ), in order to re-activate and sustain the site's residential fame throughout its history.

Erbil Citadel is well known for having 'remained an inhabited [site] throughout its history and therefore provides a unique testimony to an ancient urban form that goes back to the very first period when humankind first started to live in towns' (Brammah 2009a, 91). Yet, the evacuation step came to disavow and even disguise this fact, whereas multiple formal emphases have made to demonstrate and support it. The UNESCO Guidelines on Erbil Citadel Conservation (2014), provides a number of suggestions, setting the traditional residential trait of the site as a core for its future plan. For instance, it suggests adhering to 'taking into consideration the particular situation and specificity of Erbil Citadel' which currently holds traits of being one of the longest continually inhabited site, 'making it one of the oldest urban settlement[s] in the world...to make it the living, dynamic and self-sustaining historic centre' (UNESCO 2014, 3-5). Accordingly, 'Note on Infill Buildings' of this Report suggests that 'the construction of some [ruined] areas and empty spaces [should maintain] the continuity of the historic urban fabric...to regenerate the [residential] sense of place and urban character' (UNESCO 2014, 10).

However, the revitalisation policy did not pay attention to the demise of the site's residential traits putting its future in opposition to its history when affirming that the site's 'culture and cultural heritage will be used as vectors for development' (UNESCO 2014, 5). ‘... Its character will be enhanced by means of...tourism and leisure activities that are compatible with the historical nature of the place and its aspirations to become a World Heritage Site' (UNESCO 2014, 125) On an urban level, the suggested urban land-use also proposes new 'tourism-related accommodations, facilities and services', such as 'hotels... cafes; restaurants; souvenir shops' (UNESCO 2014, 126).

This ultimately drags the site's residential fame, as a main feature for the site identity, to come second to and 
complementary to the new tourist purpose. Socially, according to a Workshop on 'A Vision for the Future of the Citadel' for Brammah $(2009,167)$, some official social elites, particularly those who financially support restoring and maintaining some individual buildings of the site, have also been deemed the most appropriate for occupying the site henceforth instead of its indigenous people. Elites 'who can contribute to a mutually supportive society' should be given the priority to utilise the site, acting as 'guardians' of it who may be journalists, writers, historians, architects, cultural institutions, and foreign delegates. The question raised here is who could potentially act more effectively as guardians of a home more so than its indigenous residents?

Indeed, activating such plans would lead to a complete atrophy of this unique historical residential value, the value for which the site is globally well-known and which has contributed to it becoming a world heritage site. Implanting new functions for the site means nothing but changing the urban scenery of this habitation from the very historical residential to new touristic character. Accommodating new professional people also does not necessarily imply that they are more enthusiastic about this residential settlement than its indigenous people who may have shared a deep history with it for decades. Perhaps this attests to the inconsequential use of the power given to the site's authorities that led to such a destructive step. According to the key global experts on the revitalisation project, this ineligible power brought to the site more drawbacks. Through a personal email communication they have demonstrated that:

The present site management ... have even avoided having any connections with, for example, the Aga Khan Foundation. Also, the British Museum wanted to have an excavation of the Citadel, but the HCECR made the conditions so difficult that they gave up the idea ... UNESCO Iraq recently advertised for an individual consultant to develop Public Private Partnership, but whether this will actually be implemented is quite another matter...UNESCO Iraq has advertised consultancies in the past, which have never taken place.

Thus, the study here may confirm the locals' argument that a similar policy, but with different tools, has been redirected from the renovation to the revitalisation, which monopolises the mechanism of decision-making for a particular network of the site's authorities only. Then, whilst the renovation led the site to lose some of its traditional buildings, the revitalisation left the site deserted of its inhabitants. The revitalisation therefore leaves some questions unanswerable without further discussion. For instance, if the new tourist shift is planned to ultimately serve Erbil Citadel, what prevents it from keeping the site for its inhabitants? Moreover, if the future of the site is moving towards purely tourist dimensions, what are the reasons that impede the employment of more views in supporting this shift? To answer such questions, more debate should be encouraged in order to reveal the possible ramifications surrounding the aim and policy of the current evacuation.

\section{Discussion on the Evacuation Step: A Legitimate Aim, Vicious Policy}

Opening the Citadel up for global tourism is a legitimate aim which could also maintain the site culturally and economically besides boosting its cultural identity. However, it also means its decision-makers may track a completely new strategy for the Citadel's future, a strategy that is still untested and may adopt modern tools and global skills, which entails locals' views being 'out of the plan'; a strategy that facilitates drawing openended decisions towards the site as if it were owned by its authorities and not its inhabitants. Perhaps, for the site's decision-makers, due to the limited local experience, the most appropriate step for achieving its aim was the evacuation, which appears here as a double-edged sword. On the one side, the Final Report on the site in 2009 assures that the evacuation step enabled the revitalisation decision-makers to control the whole site, and thus become owned by the local authorities as a public ownership. However, on the other side, this control is in fact a matter of concern and what Hardoy and Gutman $(1991,105)$ call the tacit 'destructive management' of the historic centre that was often managed 'by those who have the greatest power to intervene' in the social and residential circumstances of the inhabitants. This also contradicts the recommendation of the World Conservation Union by in 1996 that participation of the site's inhabitants should be given legitimate prerogative recognition when planning for its cultural values (IUCN 1996).

Monk and Herscher $(2015,68)$ bring to light a kind of duplicity of standards in the policy of the evacuation which outwardly calls for improving the site's infrastructure, while implicitly dissolving its sociocultural structure. To this end, the most appropriate procedure was firstly to clear the site of its residents in order to enable and expedite the decision of making the site 'a visitorfriendly area, which in fact seems contentious. What make 
it more contentious are the tools that are used to achieve this aim. More precisely, the evacuation has 'a troubling backstory' and it has been claimed that the site suffers from a lack of infrastructure and therefore, the efforts are to maintain [these infrastructures] necessary to mitigate [their] chronic erosion problems...to ensure there would be no break in the site's continuous habitation' (Monk and Herscher 2015, 71). Consequently, the inhabitants have had to leave to facilitate the realisation of this task. However, immediately after this evacuation, the revitalisation policy sought to include the property on the WHL utilising the argument of the site's global history that evidences its global stature arguing it should therefore be a global tourist site.

Ironically, the reason behind its inclusion on the WHL is mainly due to it being 'the longest continuously inhabited site in the world', this status transformed it 'into a certified site of heritage....and tourism destination, [but] cleared of its inhabitants' (Monk and Herscher 2015, 68). The contradiction therefore is in the duplication of dealing with the significance of the residential feature of the site, which is outwardly politicised to ensure the site's inclusion on the WHL, whilst inwardly transforming it into a new synthesis of recreational and tourist purposes, such as 'hotels, restaurants, museums and galleries' (Monk and Herscher 2015, 71). What perhaps propels this argument to a higher level of credibility is that this tourist plan is also evidenced through the Implementation Action Plan (2009) in the revitalisation process, which shows the approved new urban and architectural tourist use of the site that provides different tourist utilities. As part of the evacuation decision, Monk and Herscher debated as to whether 'global tourism and heritage industry' are mutually working against inhabitants (Monk and Herscher $2015,71)$. If we answered their question, confirming that they are 'not', is marketing the Citadel as a global heritage site only achieved by cleansing it of inhabitants?

Undoubtedly, knowing the reasons that impede the locals' role here is important. Simply, it is the Iraqi conservation laws including heritage decision-making structure locally. Despite the multitude of local built heritage sites, only the Iraqi Rule of Heritage and Archaeology (2002), which is developed through the Municipal Administration Law No. 165 (1964), focuses on conservation of these sites. However, the role for achieving that, through this rule, is entirely assigned to the local authorities as administrative powers that should also work on how to present these sites to the visitor. The policy, to achieve this objective, depends on numerous points, but none of them are linked to the local community. Another law, which is the Forum of Monuments within the Antiquities and Heritage Law No. 55 (2002), prescribed inter alia, are all meant to boost the survival of the site, but again it exclusively focuses on the role of the site's authorities without reference to the role of its inhabitants. The Law comes to grant the authorities the right to possess the whole area that includes a heritage site or monument, leaving a clear rift between the top-down and the bottom-up roles in setting an integral plan for conservation.

However, the structure of the decision-making process, which can be referred to as a system in pyramid form, is perhaps also a reason why such hasty steps have been taken for the local heritage sites. Both of the above Laws keep this decision-making structure tied to political authorities (the top of the pyramid) and policy-makers of the site (the bottom of the pyramid). The general main lines of the conservation decisions are enacted at the top of the pyramid, particularly when it has some politicalcultural implications related to the place regionally, while the translation of these lines at the lower scales should be achieved at its bottom level. Within this level, different urban, regional, economic, social and rural planners, urban designers and architects should work on translating these general lines into specific dimensions, whilst the locals are out of this structure. If we knew that this structure was generalised in the whole process of decision-making locally including Kurdistan, it may justify its embodiment in the evacuation step of Erbil.

Thus, besides the fragile local experience of conservation, the roots of the mono approach in making the evacuation decision can be attributed to the local conservation laws as well as the decision-making structure. Whilst these two main motives form the backbone of this approach, each one of them departs from the policy away from of its established course that was intended to run and maintain the site potentials in an appropriate manner (UNESCO 2009). In this case, the first motive often works on politicising conservation decisions (to serve a supreme authority), and the second motive works on serving purely tourist aims (habitually relates with the misuse of granted power for the decision-makers of the site).

What makes this decision familiar in the current decision-making process of Erbil is its local spread within more than one site in recent decades, which draws upon these two motives: the politicised motive and the tourist motive. Babylon's world heritage site has suffered from the first motive, the 'politicised motive', in a very contentious conservation process in 1989, which stormed the 


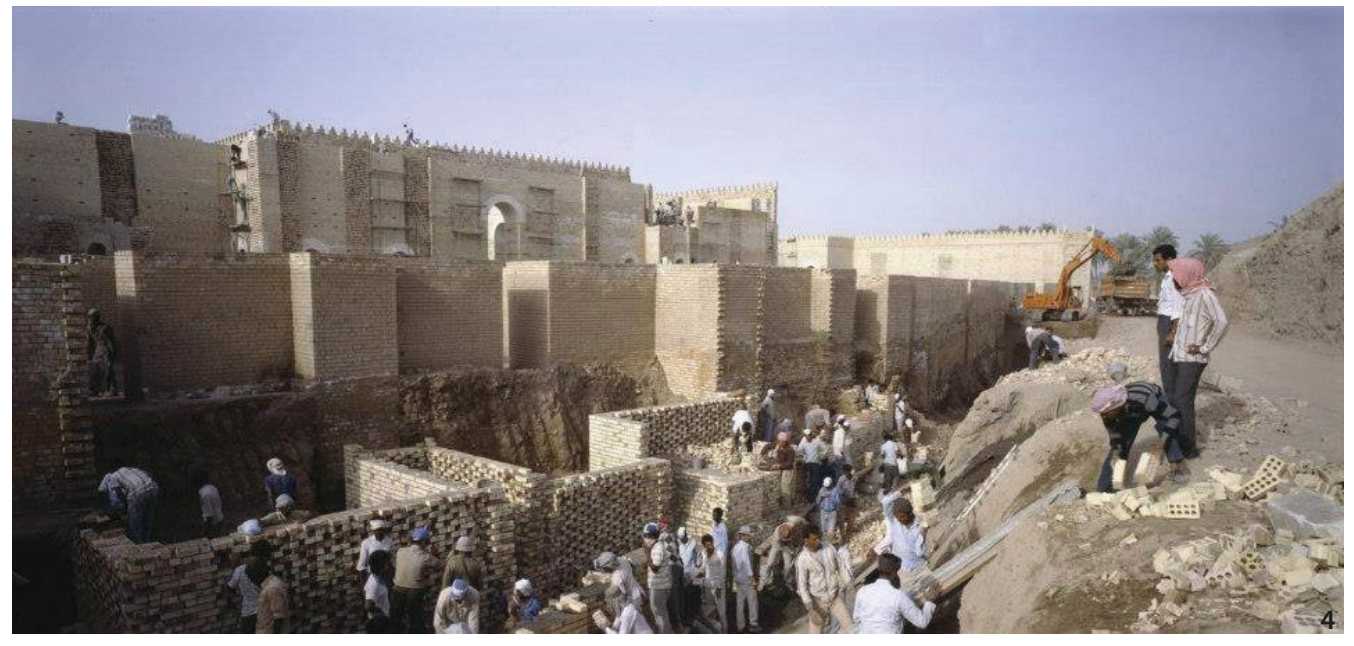

Figure 4 Digging, building and changing of the original material with modernised units, which is a decision entrusted to the site authorities (Source: archival data of Babylon's private library)

site with some decisions that, instead of buttressing its historical settings, worked on embedding in the site some symbols that denote the Iraqi political regime represented by the character of Saddam Hussein. This was 'as part of a politicised-construction program' on the site, which has subsequently resulted in 'the great detriment of the site' (UNESCO 2009, 6), and thus the exclusion of Babylon from the WHL (Allen 2013; Shirshab 2015). In this instance, the monopoly of decision-making to serve political power led to replacing a huge amount of original bricks with modern units that held some denotations glorifying that regime (Figure 4). According to Seymour (2014) and the Report of 'Bringing Babylon back from the Dead' by Damon (2013), this has resulted in the loss of huge quantities of remnants and replacing them with standardised materials completely detached from the historical architectural language of the site.

On an urban level, the conservation policy for the traditional neighbourhood 'Mahalla' of Anbareyen in Baghdad in the 1990s can represent an example of the second motive of misusing the power of decision-making to serve tourist aims. The policy aimed at re-developing the sacred traditional area, which surrounds the 'Shrine of Kadhim' by a radius of $500 \mathrm{~m}$, calling it a 'developmental maintenance circle' (or the bottom-up circle), in order to support the religious tourism of the site. It suggests demolishing the ambient ancient traditional urban fabric, and replacing it with new modern residential units. In return, a proposed local plan, (or the bottom-up circle), in response to this circle, suggests retaining this traditional fabric, as it enriches the place with a variety of cultural and historical values forming its urban privacy. Perhaps, what stands behind the power of the bottom-up circle is that the local communities of such areas are often seen as the most appropriate sample to start with, and thus to formulate such decisions (Silva and Chapagain 2013). This is justified when we know that the locals of a particular heritage environment are interrelated in the synthesis of a heritage network as an authority inherently embedded in the site over history (Chapman 2008). Therefore, their contributions, when associated with the decision-makers' contributions, would lead to a complete and integrated loop of policy-making. However, the absolute authority of the decision-makers has cancelled out this synthesis, thus leaving the loop incomplete.

What leaves the top-down circle lopsided is that it seeks to enclose the traditional organic fabric of this Mahalla within a circle of a radius $500 \mathrm{~m}$ though this fabric includes a mixture of urban symbols that reside at different distances from the Shrine. Conversely, the bottomup circle adopts a conservatory maintenance that does not work on separating the site from its surroundings or demolishing its urban symbols, but rather it draws upon selective processes of maintenance for its devastated units. However, the top-down circle has subsequently been endorsed for full execution, as evidenced by some proposals revealed after 2003, but which was then deferred due to the ensuing unsafe local circumstances. (Figure 5a, Figure 5b).

Apparently, these local examples reveal the controlling role of the authorities clearly blocking any other contributions coming from outside and hence showing indifference to such contributions. Regardless of the changes that they may make to the site's future policies, these local experiences reveal how a top-down vision misjudges any expected value of a local contribution in making heritage decisions. Even worse is to grant this 'authoritarian vision' a supreme position in deciding on the futuristic plan of heritage including its current potential and issues without 

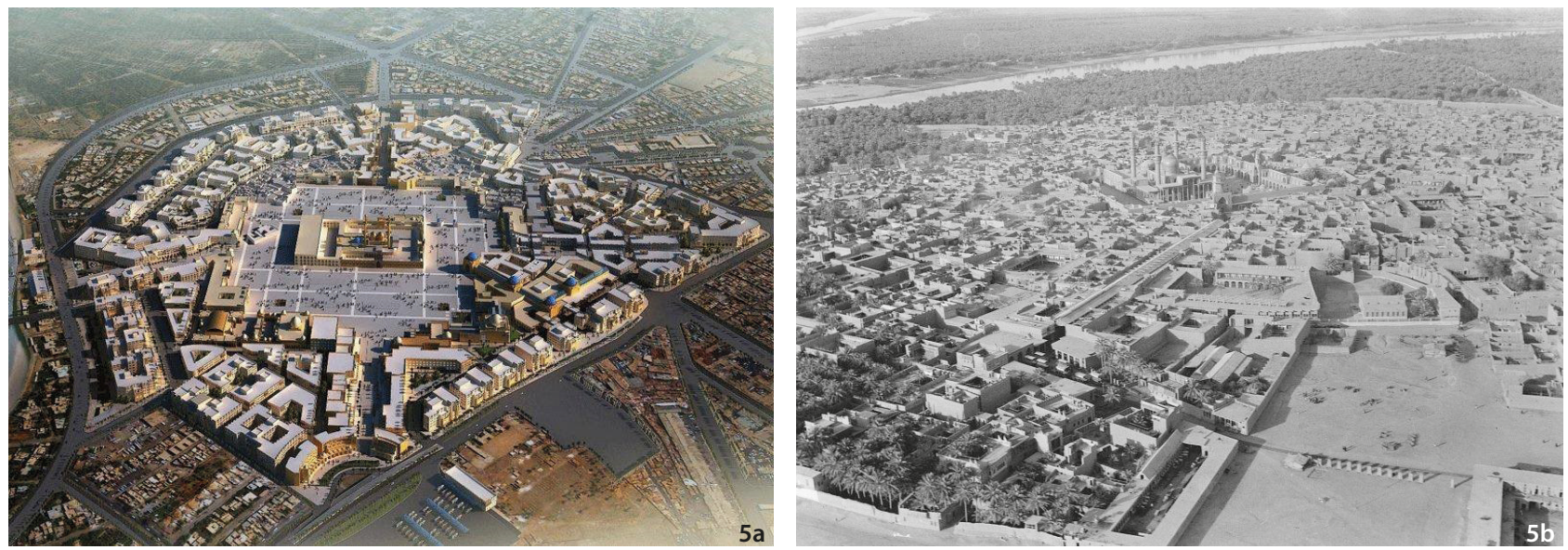

Figure 5a A proposal for the 'developmental maintenance circle' (Source: Private library of Ihsan Fathi \& Muaffaq al-Taey). Figure $5 b$ The real urban scene of the Mahalla; (Source: Private library of Ihsan Fathi \& Muaffaq al-Taey)

referring to 'whom' and 'how' decisions in such cases should be made. According to Vinas (2005), built heritage cannot be confined to a particular group of people; it belongs partly to their inhabitants and partly to those generations who care about its cultural survival. Hence, those who decide on built heritage sites should not decide on behalf of their inhabitants and carers regarding the future of these treasured sites, but it should involve them in such a process as 'a stable network [who puts] effective shared views' into heritage issues (Jordan 1990, 327).

In fact, referring to some heritage studies on some Asian conservation experiences, such as Timothy (1999), may show that the 'authoritarian vision' of some policymakers does not allow for any kind of two-way mechanism in planning for built heritage. It seems difficult for this vision to acknowledge the voices at the grassroots level of the site to equally possess a similar standing with them in the conservation process. Quoting Hampton (2005), this often leaves the value of 'listen[ing] to the voices of the local people, "the lowers"' to be subordinate to this top-down vision of policy making, resulting in misleading outcomes, and thus a state of suspicion concerning the merit they deserve to be involved in making such delicate decisions.

\section{Conclusion}

Obviously, the old tradition that authorises the conservation decision-makers as 'the knowers of everything' about the site should be substituted by a decentralised power strategy of heritage conservation policy-making. Henceforth, future heritage policies should be sifted through a two-way process of formulation, starting from top-down general guidelines, through bottom-up home-grown visions, and ending with policy-makers' decisions. The rationale behind this is that it subjects the conservation policy to a complete setup and objective review, starting from the formulation stage and ending with the assessment stage of the policy, which keeps the policy more open and flexible for future suggestions. This promotes a cultural potential-based strategy of the site, which precedes, and thus governs any decision regarding the future of the site to what sustains its history, culture and original settings. This is to say that the site authorities are also then liable for any ramifications that impede a deep-sighted strategy, or any straying away from delivering the farreaching aims.

Within Iraqi heritage, it is clear that the strict dominance of the top-down approach on the mechanisms of heritage conservation policy is far from objective, as it rules out many potential contributions, and substitutes them for a predetermined plan. This firstly often endangers 'the traditional character' of built heritage, and consequently lessens 'the sense of the place' (ICOMOS 2014, 84). Secondly, it leaves out the potential for targeting the local community in furthering the setup of the overall plans of most of these sites. Not including their views therefore results in a non-thorough knowledge or an incomplete reading of the cultural potential and historical assets of the site, and negative impacts ensue.

Iraqi local conservation laws and local heritage decision-making structures are found to be the main two factors that lead to negative impacts. While strict bureaucratic regimes are perceived as incentives for the setup of such laws and structures locally, mostly such laws and structures lead to politicising strategies to serve predetermined objectives, and consequently prejudiced outcomes. Robust ties between the policy and the conservation 
decision-makers primarily support such strategies, which often leads the conservation policy to a one-way process of formulation, abstract from many untested contributions, and thus subjecting the site to some adverse consequences. These ties therefore need to be more transparent; otherwise, they should be dissolved to allow for more efficient debates and live views that would enable the site potentials and requirements to be revisited from different perspectives.

Within the context of Erbil, its current planning challenges the dualism of traditionalism and modernity, the new and the ancient, the global and the local. This gives a clear example of how the local top-down development policies of the city are subject to change and embed the 'other' superficially. One of the key reasons behind this is the huge opening towards the Western architectural culture, which, sometimes, is imported as one 'block' into our Islamic cities that celebrate an entirely different culture and architecture, which distinguish them and their forms with their own private character and identity. Incentives for this may come from what Stansfield (2003) states in that Erbil suffered unstable environmental and political conditions after 1991, which led to an uncontrolled boom based on rapid visions, which burdened some sectors of the city with extra urban functions at the expense of other sectors that have been left semi-deserted.

The effects of this have stretched out to reach the present architecture of Erbil Citadel to suffer a state of critical transition between its past and future, challenging a state of dichotomy and contesting two different architectural assets to be fluctuating between two detached realities: 'the traditional residential' and 'the contemporary touristic'. If the renovation is assessed locally as a deliberate demolition of the site's unique Islamic characteristics, as represented by the removal of its compact organic fabric, therefore relegating it to a standardised urban planning, the evacuation may drag the global assessment of the revitalisation project into an even worse assessment in the future. It has broken the unique characteristic of the site as being the oldest site in the world to be continuously inhabited, the factor which earned the Citadel its place on the WHL, and which may now prompt a reinvestigation by UNESCO. This is to say that both the renovation and the revitalisation have been subjected to a similar process of top-down decisionmaking, but perhaps with different tools according to the circumstances surrounding each.

Thus, the primacy in heritage conservation decisionmaking should not be a monopoly for the monaural authority approach, but should be synthesised with heritage specialists as well as some local-based views through an overlapped integral loop of interactions between them. To say that the site authorities should hold the leadership baton of the conservation policy-formulation seems unacceptable for many sites today for its different destructive impacts. Synthesising the views of experts, locals and site authorities may lead to greater neutrality in the development of future policies for built heritage, thereby ensuring a more transparent focus on the site's real potential and needs.

\section{References}

Allen, Jeff. 2013. “The Renovation Project of the Ancient City of Babylon in Iraq and Returned to the World Heritage List." Middle-east, Arabs' International Newspaper, August 23.

Aljanabi, Hassan. 1987. Erbil City: An Urban Study. Mosul: University of Mosul Press.

Avrami, Erica, Randall Mason, and Marta de la Torre. 2000. Values and Heritage Conservation: Research Report. The Getty Conservation Institute: Los Angeles. Brammah, Huszar. 2009a. "Revitalisation of Erbil CitadelIraq-Phase I, Final Report: Summary of Activities and Outputs of the Project."

Brammah, Huszar. 2009b. "Revitalisation of Erbil Citadel -Iraq-, Phase I, Final Report: Implementation Action Plan."

Brammah, Michael. 2009. "Workshop on the Future of Erbil Citadel: A Vision for the Future of the Citadel."

Carlsson, Lars, and Fikret Berkes. 2005. "Co-management: Concepts and Methodological Implications." Journal of Environmental Management 75 (1): 65-76.

Chapman, Ellen. 2008. "Community, Heritage, Identity: Constructing, Performing and Consuming Welsh Identities in the US." PhD diss., Newcastle University.

Chitty, Gill, ed. 2017. Heritage, Conservation and Communities: Engagement, Participation and Capacity. Abingdon: Routledge.

Damon, Arwa. 2013. Bringing Babylon back from the Dead. CNN, April 5. Accessed August 24 2015. https:// edition.cnn.com/2013/04/04/world/meast/iraq-babylon-tourism/index.html

Ebraheem, Sharameen. 2013. "The Impact of Architectural Identity on National Branding: The Case Study of Iraqi Kurdistan.” PhD diss., Manchester Metropolitan University.

Hampton, Mark. P. 2005. "Heritage, Local Communities and Economic Development." Annals of Tourism Research 32 (3): 735-759. 
Hardoy, Jorge, E., and Margarita Gutman. 1991. “The Role of Municipal Government in the Protection of Historic Centres in Latin American Cities." Environment and Urbanisation 3 (1): 96-108.

HCECR (High Commission for Erbil Citadel Revitalisation). 2012a. "Erbil Citadel: Reinstatement of the Grand Gate."

HCECR (High Commission for Erbil Citadel Revitalisation). 2012b. "Highlights of Erbil Citadel: History and Architecture: Visitor Guide."

HCECR (High Commission for Erbil Citadel Revitalisation). 2012c. "Nomination of Erbil Citadel (Kurdistan Region, Iraq) for Inscription on the UNESCO World Heritage List; Vol. I."

Hewiston, Robert. 1987. The Heritage Industry: Britain in a Climate of Decline. London: Metheun.

Hidaka, Lucia, Tone, Ferreira. 2008. "Contemporary Theory of Conservation, by Salvador Muñoz Viñas.” City \& Time, 4 (1): 65-68.

ICOMOS. 1999. The Burra Charter: The Australia ICOMOS Charter for Places of Cultural Significance.

ICOMOS. 2008. Quebec Declaration on the Preservation of the Spirit of the Place.

ICOMOS. 2013a. The Burra Charter: The Australia ICOMOS Charter for Places of Cultural Significance, 2013.

ICOMOS. 2013b. Understanding and Assessing Cultural Significance, Practice Note, Version 1, Australia ICOMOS.

ICOMOS. 2014. "Evaluations of Nominations of Cultural and Mixed Properties: ICOMOS Report for the World Heritage Committee 38th Ordinary Session.” Doha, June 2014.

IUCN (International Union for Conservation of Nature). 1996. The World Conservation Union: Special Issue on Collaboration Management, No. 2.

Ismail, Ayoob, and Ibrahim Ngah. 2010. "Urban Planning for Small and Medium Cities in Kurdistan RegionIraq: Problems and Available Opportunities." International Journal of Engineering Science and Technology 2 (12): 7070-7077.

Jasim, Mohammed, Laura Hanks, and Katharina Borsi. 2017. “Do Really the Audience's Views Efficiently Boost Built Heritage Conservation Policies?" Athens Journal of Tourism 4 (4): 238-306.

Jokilehto, Jukka. 2017. "Engaging Conservation: Communities, Place and Capacity Building." In Conservation and Communities: Engagement, Participation and Capacity, edited by Gill Chitty, 17-33. Abingdon:
Routledge.

Jordan, Grant. 1990. "Sub-governments, Policy Communities and Networks, Refilling Old Bottles?" Journal of Theoretical Politics 2 (3): 319-332.

Kriken, John, Philip Enquist, and Richard Rapaport. 2010. City Building, Nine Planning Principles for the Twentyfirst Century. New York: Princeton Architectural Press.

Macginnis, J. 2013. "Erbil in the Cuneiform Sources: A Catalogue and Historical Assessment.” Erbil-Iraq, Kurdistan Regional Government.

Monk, Daniel, Bertrand, and Andrew Herscher. 2015. “The New Universalism: Refuges and Refugees between Global History and Voucher Humanitarianism." Grey Room (61): 71-80.

Muñoz Viñas, Salvador. 2005. Contemporary Theory of Conservation. London: Routledge.

Nicholas, Lorraine, Nadia, Brijesh Thapa, and Yong Jae Ko. N. 2009. "Residents' Perspectives of a World Heritage Site." Annals of Tourism Research 36 (3): 390-412.

Nooraddin, Hoshiar. 2012. "Architectural Identity in an Era of Change." Developing Country Studies 2(10): 81-96.

Novacek, Karel, Tomas Chabr, David Filipsky, Libor Janicek, Libor Janicek, Karel Pavelka, Petr Šída, Martin Trefny, and Pavel Vareka. 2008. "Research of the Arbil Citadel, Iraqi Kurdistan, First Season." Pamatky Archeologicke 99: 259-302.

Rebwar Ismail Ibrahim, Sabah A. Mushatat, and Mohamed Gamal Abdelmonem. 2015. "Erbil." Cities 49: $14-25$.

Rebwar Ismail Ibrahim, Sabah A. Mushatat, and Mohamed Gamal Abdelmonem. 2014. "Authenticity, Identity and Sustainability in Post-war Iraq: Reshaping the Urban Form of Erbil City." Journal of Islamic Architecture 3 (2): 58-68.

Rydin, Yvonne. 2010. Governing for Sustainable Urban Development. London: Routledge.

Seymour, Michael. 2014. Babylon: Legend, History and the Ancient City. London: I.B. Tauris \& Co Ltd.

Shirshab, Adel. 2015. "Iraq Completed the File for Reraised Babylon to the World Heritage List." Baghdad: NEWS. http://arabic.news.cn/culture/2015-01/20/ c_133931015.htm

Silva, Kapila, D. and Neel Kamal Chapagain, eds. 2013. Asian Heritage Management: Contexts, Concerns, and Prospects. London: Routledge.

SOITM (Iraqi Turkmen Human Rights Research Foundation). 2013. Report: Erbil Citadel.

Stansfield, Gareth. 2003. Iraqi Kurdistan: Political 
Development and Emergent Democracy. London: Routledge.

Taylor, Ken. 2004. "Cultural Heritage Management: A Possible Role for Charters and Principles in Asia." International Journal of Heritage Studies 10 (5): 417-433.

The Forum of Monuments within the Antiquities and Heritage Law 2002. No. 55 of 2002. Baghdad; Legal Rule.

The Municipal Administration Law No. 165 of 1964. Baghdad; Legal Rule.

Timothy, Dallen. 1999. "Participatory Planning: A View of Tourism in Indonesia." Annals of Tourism Research 26 (1): 371-391.

UNESCO 2009. International Coordination Committee for the Safeguarding of the Cultural Heritage of Iraq: Sub-Committee on Babylon: Report on Damage Assessments in Babylon.

UNESCO 2014. Erbil Citadel Conservation Guidelines and Manual for Implementation, prepared by Ms Patrizia Barucco and Ms Lorenza Nicosia.

Uriely, Natan, Aviad Israeli, and Arie Reichel. 2003. "Religious Identity and Residents' Attitudes toward Heritage Tourism Development: The Case of Nazareth Heritage." Journal of Hospitality \& Tourism Research 27 (1), 69-84.

Yasin, Salahaddin. 2011. "Influence of Modernity versus Continuity of Architectural Identity on House Façade in Erbil City" PhD diss., University of Sains Malaysia. 